\title{
NEKAJ MISLI O DVEH SLOVENSKIH ORESTEJAH
}

\author{
ANDREJA N. INKRET
}

Najnovejša slovenska gledališka uprizoritev Oresteje, kot jo je v Slovenskem narodnem gledališču Drama Ljubljana zrežiral Jernej Lorenci, je bila zamišljena kot obeležje prve profesionalne uprizoritve Ajshilove trilogije na slovenskih odrih. Predstavi, ki jo je pred dobrimi štiridesetimi leti na odru istega gledališča režiral Mile Korun, v slovenskih gledaliških analih namreč pripada pomembno mesto. ${ }^{1}$ Velja za ključno uprizoritev v obdobju tako imenovanega »slovenskega gledališkega modernizma«, ki je med drugim pomenil tudi svež in nov pristop k dramski klasiki. Korunova Oresteja je obveljala tako rekoč za eksemplaričen primer gledališke umetnosti, ki spremeni svojo »vse preveč izraženo literarno naravo« in se v prenovljeni obliki »začne z avtorskim režijskim konceptom, z idejo uprizoritve, ki jo morajo harmonično podpreti in izoblikovati igra, scenografija, kostumografija in glasba «. ${ }^{2}$ Korunova Oresteja pa ne pomeni le enega izmed prelomov s t. i. »literarnim«, dramskemu besedilu podrejenim gledališčem, pač pa tudi radikalen zarez v tradicijo akademskih, historicističnih gledaliških pristopov h grški tragediji. ${ }^{3}$ Od Oresteje dalje je inventiven režijski koncept, nevezan na vnaprejšnje ideje in predstave o grški drami in gledališču, obvezna izhodiščna točka pri postavitvi antičnih dram na sodobni oder. In če se dandanes gledalcu lahko zdi, da gledališki ustvarjalci svoje odrske interpretacije vse prevečkrat neproduktivno ustvarjajo same sebi v namen, mimo klasičnih dramskih besedil, ki jih postavljajo na oder, lahko brez zadržkov zapišemo, da Jernej Lorenci s postavitvijo Ajshilove trilogije sledi Korunovemu zgledu v najboljšem pomenu besede. Postavitev Oresteje, kot jo je zasnoval s sodelavci, se zdi zahtevna in domišljena interpretacija, ki ne skuša za vsako ceno prevladati nad

1 Glej Mojca Kreft, ur., Oresteja 68 (Ljubljana: Slovenski gledališki muzej, 2008). Obsežna monografija, ki je izšla ob štiridesetletnici uprizoritve, vsebuje tudi DVD s televizijskim posnetkom predstave.

2 Bojan Štih, »Slovenski gledališki trenutek, " Gledališki list SNG Drama Ljubljana XLVII (sez. 1967/68): 9.

3 Pred Korunovo postavitvijo Ajshilove Oresteje velja omeniti predvsem Evripidovo Medejo, ki so jo leta 1964 (v prevodu Frana Bradača) igrali v ljubljanski Drami pod režijsko taktirko Andreja Hienga. Ta sicer ni imela takšnega vpliva in veljave kot Oresteja, a je vendarle izzvenela brez "tradicionalne patetičnosti in 'koturna'«, Kajetan Gantar, »Euripides in Aristofanes v Ljubljanski Drami, « Argo IV-VI (1965-7): 100-1. Prim. tudi Polde Bibič, Izgon: pripoved o uspehih, spopadih in padcih $v$ Štihovem obdobju ljubljanske Drame (Ljubljana: Nova revija Slovenski gledališki muzej, 2003), 432. 
besedilom, pač pa ga nadgrajuje tako, da stopi z njim v ustvarjalen dialog in ob tem suvereno gradi lasten gledališki jezik.

Razlike med dvema odrskima interpretacijama istega besedila, postavljenima $\mathrm{v}$ isto gledališko hišo, a v dve različni državi, politična sistema in socialno ter kulturno klimo, so več kot zanimive. V tem kratkem zapisu lahko zabeležimo le nekaj opazk.

Kritiki so se nad Orestejo Mileta Koruna navduševali v prvi vrsti zaradi avtentičnega gledališkega jezika. Opisovali so ga kot »totalno«, »okrutno« oziroma »kruto«, »ritualizirano« oziroma »ritualno « gledališče. ${ }^{4}$ Verjetno ni naključje, da je bil kot najbolj uspel element prve profesionalne Oresteje izpostavljen zbor, tisti element torej, ki sam po sebi simbolizira določeno ritualno komponento antične drame. Korunov zbor je bil nekaj posebnega tako $\mathrm{v}$ gibu ${ }^{5}$ kot $\mathrm{v}$ melodičnem govoru, glasbi, ki so jo povsem brez inštrumentov ustvarjali igralci (komponist je bil Darijan Božič). Glasbila so bila njihovi glasovi, vzkliki, vzdihi, šepetanja, pa tudi noge, ki so udarjale ob tla, roke, ki so bíle kamen ob kamen. Izpostavimo lahko predvsem zbor v Agamemnonu; režiser se je odločil za mlade igralce. ${ }^{6}$ Ti so nepozabni predvsem na mestu, ko - v vedno bolj ekstatičnem ritmu - pripovedujejo zgodbo o Agamemnonovem žrtvovanju Ifigenije (slika 1). Zdi se, kot bi bila ritualna dimenzija tragedije na novo ustvarjena.

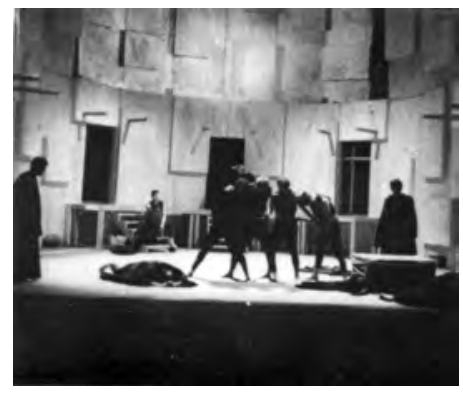

1 Zbor (Danilo Benedičič, Polde Bibič, Boris Cavazza, Janez Hočevar, Tone Homar, Kristijan Muck, Radko Polič, Pavle Rakovec, Matjaž Turk, Dare Valič) v Agamemnonu, 1968. Avtor Marijan Pal (z dovoljenjem Slovenskega gledališkega muzeja).

Jernej Lorenci štiri desetletja kasneje med pripravami na novo uprizoritev Oresteje pride do povsem drugačnih, lahko bi rekli diametralno nasprotnih spoznanj in inspiracij. Na tiskovni konferenci pred premiero poudari, da je prav z Ajshilom dokončno izgubil romantično vero $v$ antično gledališče in dramatiko »kot

$4 \quad$ Vse kritike in zapisi o predstavi so zbrani v monografiji Oresteja 68 (glej op. 1).

5 Kot v svojem dnevniku piše režiser, je nova ideja zbora nastala predvsem kot nasprotovanje postavitvam, ki so sledile historicističnim rekonstrukcijam antičnega gledališča; tako se »upor zoper ustaljeni način kaže kot nasprotovanje tisti zoprni geometriji, s katero so ..., v glavnem, reševali vsebinske in oblikovne probleme antičnega zbora«; Mile Korun, »Zapiski iz režijskega dnevnika o predstavi Aishilove 'Oresteie’ v ljubljanski Drami leta 1967. in 1968.,« v: Antički teatar na tlu Jugoslavije (Novi Sad: Matica srpska, 1981), 339; besedilo je objavljeno tudi v M. Korun, Biti $z$ igro (Ljubljana: Mestno gledališče ljubljansko, 2006), 107-13.

6 Tudi o dilemah glede identitete zboristov piše Korun v svojem dnevniku (glej opombo zgoraj). 
2 Tantal (Igor Samobor) v Agamemnonu, 2009. Avtor Peter Uhan ( $\mathrm{z}$ dovoljenjem Slovenskega narodnega gledališča Drama Ljubljana).

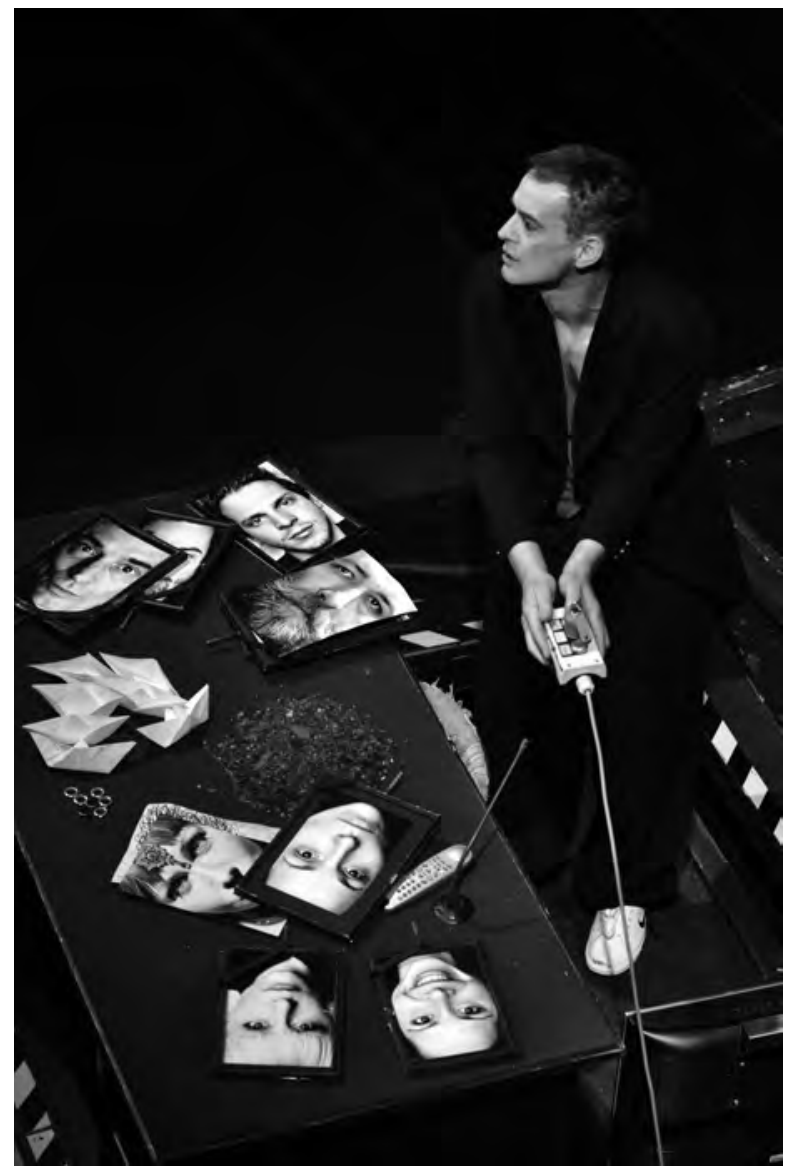

poslednjo oazo predreligioznega in predideološkega gledališča oziroma rituala«? Morda gre ravno $\mathrm{v}$ tem iskati razlog, da je zbor, simbol ritualnega $\mathrm{v}$ grškem gledališču, v najnovejši slovenski Oresteji tako rekoč izkoreninjen in tekom predstave ustvarjen na novo. ${ }^{8}$ Večino verzov, ki jih je Ajshil pripisal zboru, izgovarja en sam igralec; ta upodablja Tantala, prednika Pelopidov. V njegovi vlogi bi le stežka našli kaj ekstatično ritualnega. Tantal je moderen, racionalen tip, ki uraduje za svojo mizo ob pomoči modernih medijev, predvsem fotografij in velikega televizijskega zaslona. Med pripovedovanjem o žrtvovanju Ifigenije v Agamemnonu, na primer, dogodke sede nekam pedantno ponazarja s fotografijami osrednjih protagonistov, ki jih kaže gledalcem (slika 2). Tantal je na odru prisoten praktično skozi celotno predstavo; med dogajanjem se mu najprej pridruži Ifigenija in kasneje tudi vsi junaki, ki umrejo nasilne smrti (Agamemnon, Kasandra, Klitajmestra, Ajgist, tudi Elektra, ki na

Slavko Pezdir, »Prehod k svetlobi brez perspektive,« Delo, 17. 1. 2009.

8 V gledališkem listu sicer zasledimo zbor med dramskimi osebami, a igralci, ki naj bi ga predstavljali, se na odru pojavijo le za kratek čas, praktično samo kot statisti. 
koncu Prinašalk pitnih darov naredi samomor). V zadnjem delu Tantal in vsi umorjeni predstavljajo Erinije. Njihov konec je strašen. Atena jih - medtem ko govori Ajshilove besede o spravi - zapre v ogromno transparentno komoro. Pitija v edino odprtino te sicer neprepustne konstrukcije namesti veliko cev, ki na drugem koncu sega do izpuha ekstravagantnega rdečega dvoseda, s katerim se je prerokinja pripeljala na oder. Ko vključi motor avtomobila, se Erinije počasi zadušijo.

Zanimivo je, da se obe, tako najnovejša kot prva profesionalna uprizoritev Oresteje končata pesimistično. Orest je - kot je predvidel Ajshil - v obeh predstavah oproščen krivde, a v nobeni po razsodbi ne odide s prizorišča. Njegova zgodba in usoda po oprostitvi je $\mathrm{v}$ obeh verzijah problematizirana oziroma dodatno poantirana, pri čemer ključno vlogo odigrajo Erinije. A vendar je med obema Orestoma in njihovima zgodbama po razsodbi bistvena, ključna razlika. Leta 1968 Orest, zami-

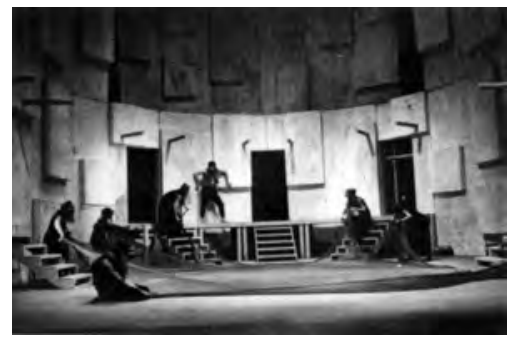

3 Orest (Polde Bibič) in Erinije (Štefka Drolc, Angelca Hlebce, Ivanka Mežan, Jerica Mrzel, Mihaela Novak, Mojca Ribič, Helena Šobar-Zajc) v Spravi (Evmenide), 1968. Avtor Marijan Pal (z dovoljenjem Slovenskega gledališkega muzeja).

šljen, temačen tip v podobi mladega Poldeta Bibiča, ${ }^{9}$ ostane povsem na koncu na prizorišču sam. Zaplete se v veliko črno mrežo, ki so jo na odru pustile Erinije, zdaj Evmenide. Gre seveda za natančno tisto mrežo, v katero so boginje maščevanja skozi tretji del trilogije neumorno lovile morilca lastne matere (slika 3). Zdi se, da kljub oprostilni razsodbi in dobrohotnim Evmenidam Orest ne more ubežati Erinijam, ki so zdaj v prvi vrsti njegove lastne moralne dileme, vprašanja, dvomi. Čeprav je bil s strani boginje Atene in atenskega ljudstva tako rekoč uradno spoznan za nedolžnega, sam v sebi ostaja ujetnik »srditih materinih psic«. ${ }^{10}$ Orest leta 2009 je diametralno nasproten. Ne le smrt matere Klitajmestre, tudi grozoviti umor Erinij ne pokvari njegovega zmagoslavja. Da je trendovski mladenič, kot ga upodablja Aljaž Jovanović, ravnodušen in nekam plehek zmagovalec, postane jasno, ko mu po strašni eksekuciji boginj maščevanja Apolon položi na glavo papirnato krono. Kmalu po tem že nonšalantno izgovarja zadnje besede, ki mu jih je pripisal Ajshil (slika 4). Povsem na koncu se s prizorišča s samovšečnim nasmehom, med mahanjem občinstvu odpelje v istem rdečem dvosedu, ki je povzročil smrt Erinij.

9 Josip Vidmar v kritiki Oresteje (Delo, 25. 3. 1968) zapiše zanimivo opazko, da Bibič kot »igralec temnega človeškega tipa« ni primerna izbira za »med vsemi svojimi vrstniki človeško najfinejšega« Oresta.

10 Prinašalke pitnih darov, 1054 (prev. Marko Marinčič). 


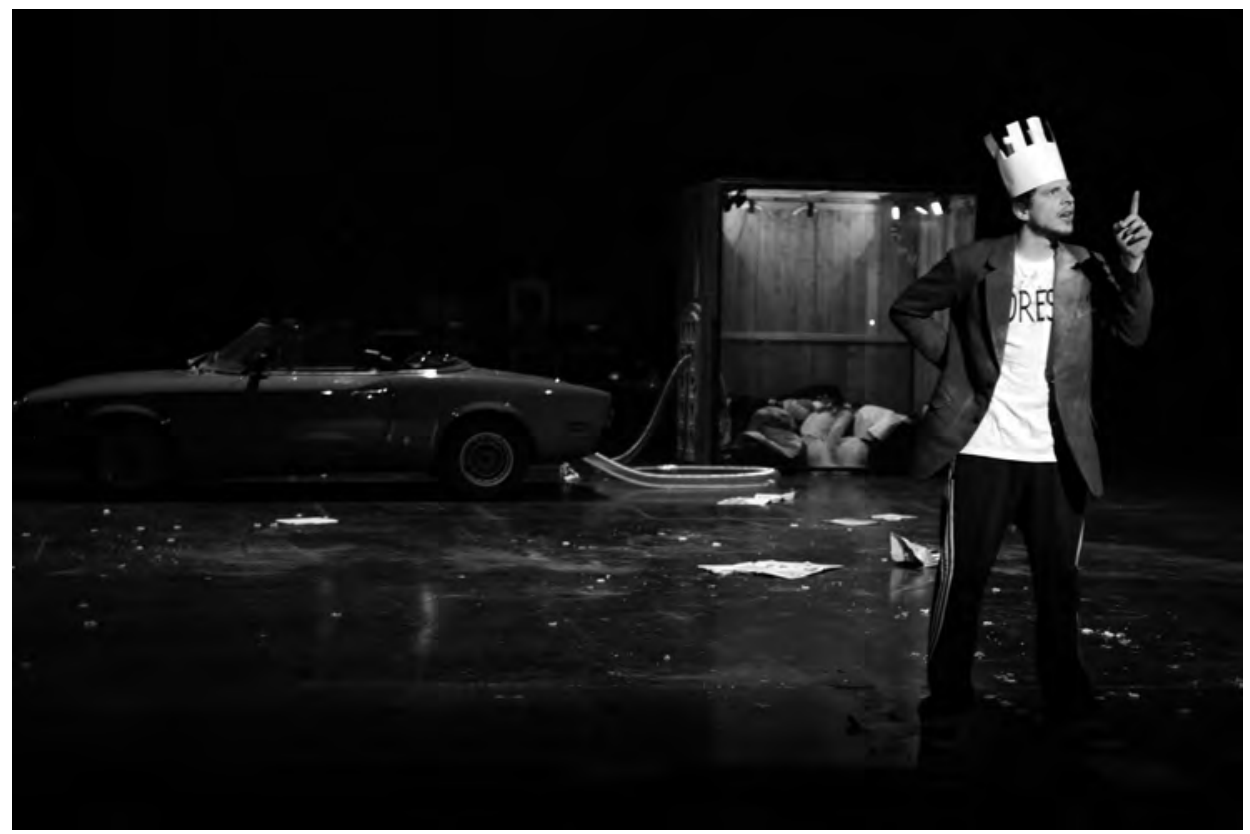

4 Orest (Aljaž Jovanović) v Evmenidah, 2009. Avtor Tone Stojko (z dovoljenjem Slovenskega narodnega gledališča Drama Ljubljana)

Nonšalantni Orest v rdečem športnem avtomobilu in njegova različica izpred štiridesetih let, v mreže Erinij zapleteni dvomljivec, sta seveda metafori, ki ju lahko razumemo na več načinov. Ko premišljamo o dveh različnih, čeprav časovno vendarle ne tako zelo oddaljenih Orestejah, nam morda lahko Oresta osvetlita tudi veliko razliko v odzivih, ki sta jih ob nastanku doživeli obe gledališki uprizoritvi. Če je še prezgodaj, da bi govorili o mestu, ki ga bo najnovejša Oresteja zasedla v slovenski gledališki zgodovini, je vendarle že jasno, da v sodobnih množičnih občilih $\mathrm{v}$ času nastanka ni spodbudila toliko poglobljenih kritik in komentarjev kot njena slavna predhodnica. Dve različni upodobitvi in usodi Ajshilovega Oresta nas opomnita, da največji razlog za to tiči v spremenjeni družbeno-kulturni klimi. Orest, zapleten v mreže dvomov in moralnih dilem, je umetnost obupno potreboval. Orest, ki sta mu za zadovoljen nasmeh potrebna le papirnata krona in dober avtomobil, ne ve več, kaj bi z njo počel. ${ }^{11}$

11 Prva različica tega prispevka je (v angleškem jeziku) nastala za revijo Eirene, Studia Graeca et Latina (Theatralia - Jean-Pierre Vernant), 45 (2009). 